P-ISSN: 2615-1723

E-ISSN: 2615-1766

April 2018
Jurnal Riset Pendidikan Dasar

1 ( 1), ( 2018) 34-39

Submitted: Februari, Accepted: Maret, Published: April

\title{
PENGARUH PENGGUNAAN MEDIA ELEKTRONIK LCD TERHADAP PRESTASI BELAJAR ILMU PENGETAHUAN SOSIAL SISWA KELAS V
}

\author{
Abustan*, Nawir \\ Program Studi Magister Pendidikan Dasar, Pascasarjana Universitas Muhammadiyah Makassar, \\ Indonesia
}

*Korespondensi. E-mail: Abustan3112@gmail.com

\begin{abstract}
Abstrak
Penelitian ini dilaksanakan untuk mengetahui pengaruh media elektronik LCD terhadap prestasi belajar Ilmu Pengetahuan Sosial Siswa Kelas V Sekolah Dasar. Tujuannya untuk mengungkapkan pengaruh media elektronik LCD terhadap prestasi penggunaan belajar Ilmu Pengetahuan Sosial Siswa kelas V Sekolah Dasar. Jenis penelitian yang digunakan adalah penelitian pre-experiment yaitu rancangan penelitian eksperimen yang hanya mempergunakan kelompok eksperimen saja, tanpa kelompok komtrol (pembanding) sampel subyek dipilih seadanya tanpa mempergunakan randomisasi. Rancangan yang digunakan adalah "One Group Design Pretest-Postest". Pembelajaran diukur sebelum dan sesudah pemberian perlakuan. Jumlah populasi hanya 25 siswa. Maka dalam penentuan sampel hanya menggunakan kelompok eksperimen saja tanpa kelompok kontrol (perbandingan), subyek dipilih tanpa mempergunakan randomosasi. Pengumpulan data dilakukan dengan mengunakan instrumen-instrumen yang sudah disebutkan diatas yaitu hasil ulangan harian siswa dan respon siswa/ pengisian angket siswa. Data yang dikumpulkan akan dianalisis secara kualitatif dan kuantitatif. Skor rata-rata hasil belajar IPS siswa yang diajar sebelum penggunaan media elektronik LCD (Pretest) Sekolah Dasar adalah bervariasi dengan hasil belajar rata-rata $71,4 \%$ dengan standar deviasi 7,788. Sedangkan Skor rata-rata hasil belajar IPS siswa yang diajar setelah (Posttest) penggunaan media elektronik LCD Sekolah Dasar adalah bervariasi juga dengan hasil belajar rata-rata 78,84\% dengan standar deviasi 7,949. Berdasarkan pembahasan yang telah diuraikan, dapat disimpulkan bahwa hasil belajar IPS meningkat setelah diterapkan penggunaan media elektronik LCD pada proses belajar mengajar.
\end{abstract}

Kata Kunci: Penggunaan Media elektronik LCD, Prestasi Belajar

\section{EFFECT OF USE OF ELECTRONIC LCD MEDIA ON ACHIEVEMENT OF LEARNING SCIENCE SOCIAL KNOWLEDGE STUDENTS V}

\begin{abstract}
This research was conducted to find out the influence of LCD electronic media to the learning achievement of Social Science of Grade V Elementary School Students. The objective is to reveal the influence of LCD electronic media on the achievement of learning Social Sciences of Grade V Elementary School students. The type of research used is preexperiment or pre-experiment research that is experimental research design which only use experiment group only, without group of controller (comparison) sample of selected subjects pickup without using randomization. The design used is "One Group Design Pretest-Posttest". Learning is measured before and after treatment. The population is only 25 students. So in the sample determination using only the experimental group alone without the control group (comparison), the subjects were selected without using randomosatio . Data collection is done by using the instruments mentioned above that are result of student's daily test and student's response / student questionnaire filling. The data
\end{abstract}

Copyright $@ 2018$, JRPD, ISSN 2615 - 1723 (Print), ISSN 2615 - 1766 (Online) 
collected will be analyzed qualitatively and quantitatively. The average score of students' IPS learning outcomes taught prior to the use of electronic LCD media (Pretest) Primary Schools was varied with an average learning outcome of $71.4 \%$ with a standard deviation of 7.788. While the mean score of IPS learning outcomes of students who were taught after (Posttest) use of electronic media LCD Primary School is varied also with the average learning outcome 78.84\% with standard deviation of 7.949. Based on the discussion that has been described, it can be concluded that the results of IPS learning increased after applied the use of LCD electronic media on the learning process.

Keywords: Use of LCD Electronic Media, Learning Achievement

\section{PENDAHULUAN}

Ilmu Pengetahuan Sosial merupakan mata pelajaran yang telah diajarkan pada jenjang pendidikan, mulai dari jenjang pendidikan sekolah dasar sampai dengan perguruan tinggi. Penguasaan keterampilan pembelajaran Ilmu Pengetahuan Sosial tidak dapat diperoleh secara sengaja (melalui latihan intensif).Penguasaan keterampilan pembelajaran Ilmu Pengetahuan Sosial diperoleh secara optimal melalui pembelajaran sejak disekolah dasar.Hal ini sejalan dengan isi kurikulum tingkat satuan pendidikan (KTSP) bahwa kompetensi dasar yang harus dikuasai oleh semua siswa dalam pembelajaran ilmu pengetahuan sosial.

Tujuan pokok pengajaran pengetahuan sosial, yaitu: 1. Memberikan pengetahuan kepada manusia bagaimana bersikap terhadap benda-benda disekitarnya, 2. Memberikan pengetahuan kepada manusia bagaimana cara berhubungan dengan manusia lain, 3. Memberikan pengetahuan kepada manusia bagaimana cara berhubungan dengan Tuhannya.

Dari uraian diatas, dapat disumsikan bahwa mata pelajaran pengetahuan sosial mempunyai nilai yang strategis dan penting dalam mempersiapkan sumberdaya manusia yang unggul, handal, dan bermoral sejak dini.

Keberhasilan proses pembelajaran merupakan hal utama yang didambakan dalam melaksanakan pendidikan di sekolah. Dalam proses pembelajaran, komponen utama adalah guru dan siswa. Agar proses pembelajaran berhasil, guru diharapkan mampu menerapkan metode yang tepat dan sesuai dengan pengajaran Ilmu Pengetahuan Sosial, guru diharapkan pula menggunakan media pembelajaran yang tepat sehingga dapat merangsang motivasi belajar siswa.

Seiring dengan perkembangan zaman, banyak media pembelajaran modern yang dapat digunakan dalam pembelajaran, termasuk menggunakan komputer dan LCD.Penggunaan komputer sebagai media informasi dan komunikasi massa sudah semakin populer, bahkan hampir setiap pelajar atau masyarakat umum perkotaan telah menggunakan tersebut.

Diera modern seperti sekarang ini, banyak yang harus kita ikuti sesuai tuntunan zaman yang serba canggih.Apalagi jika berkaitan dengan dunia pendidikan.Sistem pembelajaran pada zaman sekarang sudah sangat berbeda jauh dibanding dengan sistem belajar yang masih terkesan tradisional. Komponen-komponen untuk menunjuang berlangsungnya proses belajar mengajar juga sudah dilengkapi dengan berbagai alat teknologi. Tujuan utama penggunaan teknologi di dalam sistem pembelajaran adalah untuk memudahkan dan mengefektifkan pembelajaran agar menjadi lebih baik dari sebelumnya dalam waktu dan kondisi yang lebih baik.Salah satu media yang digunakan dalam pembelajaran adalah LCD (Liquid Crystal Display).

Berdasarkan uraian permasalahan pada latar belakang di atas, maka calon peneliti merasa tertarik untuk mengangkat permasalahan mengenai pengaruh media elektronik LCD dalam pembelajaran terhadap prestasi belajar Ilmu Pengetahuan Sosial.Sekolah yang dipilih sebagai tempat penelitian adalah SD Inpres Pattallassang 
Kecamatan Pattallassang Kabupaten Gowa. Alasan memilih sekolah ini adalah didasari dengan pertimbangan bahwa disekolah tersebut belum pernah ada penelitian yang berkaitan dengan masalah yang akan diteliti.

Media berasal dari bahasa latin "medius" yang secara harfiah berarti "tengah", perantara atau "pengantar", pesan dari pengirim kepada penerima. Menurut Gerlach dan Ely (1971) dalam Arsyad (2007:3) mengatakan bahwa media apabila dipahami secara garis besar adalah manusia, materi atau kejadian yang membangun kondisi, sehingga membuat murid mampu memperoleh pengetahuan, keterampilan atau sikap.

LCD (Liquid Crystal Display) adalah salah satu metode tampilan yang menggunakanpanel-panel kristal cair sebagai pembentuk gambar. Pada LCD Projector, gambar yang di layar dibentuk dari 3 buah LCD Panel (Red, Green, Blue) yang masingmasing membentuk element gambar Merah, Hijau dan Biru. Dari ketiga element gambar tersebut lalu disatukan lewat prisma dan kemudian difokuskan ke lensa dan diteruskan ke layar.Dalam hal ini LCD Panel seperti deretan jendela-jendela yang bisa membukatutup, dengan sudut bukaan dari tertutup rapat hingga membuka lebar, lalu disorot oleh lampu dari belakang.Dari kombinasi susunan jendela-jendela yang terbuka dan tertutup tersebut, terbentuklah sebuah gambar.

Bentuk umun dari media gamabar terangkum dalam pengertian dari media grafis. Karena media gambara merupakan bagian dari pembuatan media grafis. Sebelum kita nengetahui lebih lanjut mengenai media gambar ada baiknya kita mengetahui lebih dahulu pengertian dari media grafis.

Menurut (I Made Tegeh, 2008) media grafis atau graphic material adalah suatu media visual yang menggunakan titik-titik, garis-garis, gambar-gambar, tulisan, atau simbol visual yang lain dengan maksud untuk menikthisarkan, menggambarkan, dan merangkum suatu ide, data kejadian. Batasan tersebut memberi gambaran bahwa media grafis merupakan media dua dimensi yang dapat dinikmati dengan menggunakan indra pengelihatan.

\section{METODE}

Jenis penelitianyang digunakan adalah penelitian pra-eksperimen atau pre-experiment yaitu rancangan penelitian eksperimen yang hanya mempergunakan kelompok eksperimen saja, tanpa kelompok komtrol (pembanding) sampel subyek dipilih seadanya tanpa mempergunakan randomisasi.Rancanganyang digunakanadalah "One Group Design PretestPostest".Pembelajaran diukur sebelumdan sesudah pemberian perlakuan.Adapun yang menjadi subjek penelitian ini adalah seluruh siswa kelas V Sekolah Dasar. Berdasarkan data yang diperoleh dari guru kelas $\mathrm{V}$ yang terdapat pada tahun 2014-2015 (semester genap) di peroleh jumlah keseluruhan siswa adalah 25 siswa.

Data yang dikumpulkan akan dianalisis secara kualitatif dan kuantitatif. Data hasil observasi dan respon siswa akan dianalisis secara kualitatif sedangkan data mengenai hasil belajar akan dianalisis secara kuantitatif dengan menggunakan statistik deskriptif dan statistik inferensial.

\section{HASIL DAN PEMBAHASAN}

\section{Hasil Analisis Statistika Deskriptif}

a. Hasil Belajar siswa kelas $V$ Sekolah Dasarsebelum menggunakan media elektronik $L C D$.

Dari hasil analisis nilai tes hasil belajar yang menunjukkan hasil belajar Ilmu Pengetahuan Sosial Siswa Kelas V.B SD Inpres Pattallassang, Kecamatan Pattallasssang, Kabupaten Gowa yang tidak menggunakan madia elektronik LCD akan di sajikan pada lampiran.

Berdasarkan pada lampiran tersebut, Dari hasil analisis statistika deskriptif (SPSS) diperoleh rangkuman nilai hasil belajar Ilmu 
Pengetahuan Sosial siswa kelas V.B SD Inpres pattallassang, kecamatan Pattallassang, Kabupaten Gowa seperti ditunjukkan pada Tabel 1.

Jika keseluruhan nilai hasil belajar Ilmu Pengetahuan Sosia, maka distribusi frekuensi, presentase, serta kategori hasil belajar siswa kelas V Sekolah Dasar yang tidak menggunakan media elektronik LCD ditunjukkan pada Tabel 2.
Tabel 1 Statistik Skor Hasil Belajar Si

\begin{tabular}{|c|c|}
\hline Statistik & Nilai Statistik \\
\hline Jumlah murid & 25 \\
Nilai ideal & 100 \\
Nilai maksimum & 100 \\
Nilai minimum & 40 \\
Rentang nilai & 60 \\
Nilai rata-rata & 71,6 \\
\hline
\end{tabular}

Tabel 2 Statistik Frekuensi dan Persentase Skor Hasil Belajar Pre Test

\begin{tabular}{ccccc}
\hline No & Nilai & Kategori & Frekuensi & Persentase (\%) \\
\hline 1 & $0-45$ & Sangat rendah & 1 & $4 \%$ \\
2 & $46-54$ & Rendah & 2 & $8 \%$ \\
3 & $55-69$ & Sedang & 9 & $36 \%$ \\
4 & $70-84$ & Tinggi & 5 & $20 \%$ \\
5 & $85-100$ & Sangat tinggi & 8 & $32 \%$ \\
\hline & Jumlah & & 25 & 100 \\
\hline
\end{tabular}

Berdasarkan tabel 2 diperoleh bahwa dari 25 orang jumlah siswakelas V Sekolah Dasar. Terdapat 1 murid (4\%) yang berada pada kategori sangat rendah, 2 murid $(8 \%)$ yang berada pada kategori rendah, 9 murid (36\%) yang berada pada kategori sedang, 5 murid (20\%) yang berada pada kategori tinggi, dan 8 murid (32\%) berada pada kategori sangat tinggi. Hal ini disebabkan karena masih kurangnya minat dan perhatian belajar murid serta proses pembelajaran di dominasi oleh murid yang pintar saja. Pada hasil belajar Pre Test adalah 71,4 dari nilai ideal yang mungkin dicapai murid yaitu 100 berada pada interval 70-84. Dengan demikian dapat disimpulkan bahwa hasil belajar Siswakelas V Sekolah Dasar setelah dilaksanakan tindakan pada hasil belajar Pre Test pada kategori sedang.

b. Hasil Belajar siswa kelas V Sekolah Dasar setelah menggunakan media elektronik LCD.

Dari analisis nilai tes hasil belajar yang menunjukkan hasil belajar Ilmu Pengetahuan
Sosial siswa kelas V Sekolah Dasar setelah menggunakan madia elektronik LCD akan di sajikan pada lampiran.

Berdasarkan pada lampiran tersebut, Dari hasil analisis statistika deskriptif (SPSS) diperoleh rangkuman nilai hasil belajar Ilmu Pengetahuan Sosial siswakelas V Sekolah Dasar seperti ditunjukkan pada tabel 3 berikut:

Tabel 3 Statistik Skor Hasil Belajar Post Test Siswa siswa kelas V Sekolah Dasar

\begin{tabular}{cc}
\hline Statistik & Nilai Statistik \\
\hline Jumlah murid & 25 \\
Nilai ideal & 100 \\
Nilai maksimum & 100 \\
Nilai minimum & 40 \\
Rentang nilai & 60 \\
\hline Nilai rata-rata & 78,84 \\
\hline
\end{tabular}

Distribusi frekuensi, presentase, serta kategori hasil belajar siswa kelas V Sekolah Dasar setelah menggunakan media elektronik LCD ditunjukkan pada Tabel 4. 
Jurnal Riset Pendidikan Dasar, 01 ( 1), April 2018 ( 35-39)

Abustan, Nawir

Tabel 4 Statistik Frekuensi dan Persentase Skor Hasil Belajar Post Test

\begin{tabular}{ccccc}
\hline No & Nilai & Kategori & Frekuensi & Persentase (\%) \\
\hline 1 & $0-45$ & Sangat rendah & 1 & $4 \%$ \\
2 & $46-54$ & Rendah & 1 & $4 \%$ \\
3 & $55-69$ & Sedang & 1 & $4 \%$ \\
4 & $70-84$ & Tinggi & 10 & $40 \%$ \\
5 & $85-100$ & Sangat tinggi & 12 & $48 \%$ \\
\hline \multicolumn{7}{r}{ Jumlah } & & 25 & 100 \\
\hline
\end{tabular}

Berdasarkan tabel 4 diperoleh bahwa dari 25 orang jumlah siswakelas V Sekolah Dasar terdapat 1 murid (4\%) yang berada pada kategori rendah, 2 murid (8\%) yang berada pada kategori sedang, 10 murid (40\%) yang berada pada kategori tinggi, dan 12 murid (48\%) berada pada kategori sangat tinggi.

Nilai hasil belajar murid kelas V.B SD Inpres Pattallassang, Kecamatan Pattallassang, Kabupaten Gowa pada post test adalah 78,84 dari nilai ideal yang mungkin dicapai murid yaitu 100 berada pada interval 55 - 69. Dengan demikian dapat disimpulkan bahwa hasil belajar siswakelas V Sekolah Dasar.

\section{SIMPULAN}

Berdasarkan pada uraian dan pembahasan tersebut, maka dalam hal ini penulis menarik kesimpulan, sebagai berikut: (1). Skor rata-rata hasil belajar IPS siswa yang diajar sebelum penggunaan media elektronik LCD siswa kelas V Sekolah Dasaradalah bervariasi dengan hasil belajar rata-rata $71,4 \%$ dengan standar deviasi 7,788. (2). Skor ratarata hasil belajar IPS siswa yang diajar setelah penggunaan media elektronik LCD siswa kelas V Sekolah Dasar adalah bervariasi juga dengan hasil belajar rata-rata 78,84\% dengan standar deviasi 7,949. (3). Dari analisis data hasil belajar siswa terdapat perbedaan rata-rata hasil belajar yang signifikan yaitu $7,24 \%$. Sehingga setelah dilakukan pengujian hipotesis dengan menggunakan uji-t, maka hasilnya $H O$ diterima atau $H 1$ ditolak, artinya terdapat pengaruh penggunaan media elektronik LCD terhadap prestasi belajar ilmu pengetahuan sosial siswa kelas V Sekolah Dasar.

Saran yang diberikan yaitu sehubungan dengan hasil penelitian yang dikemukakan, serta implikasinya dalam upaya peningkatan hasil belajar IPS, maka penulis menyarankan: (1). Dalam upaya peningkatan hasil belajar siswa disemua jenjang pendidikan dan khususnya dijenjang sekolah dasar, salah satu upaya yang dapat dilakukan adalah menerapkan pembelajaran penggunaan media elektronik LCD untuk meningkatkan hasil belajar siswa. (2). Hasil penelitian ini menunjukkan bahwa pembelajaran dengan menggunakan media elektronik LCD memberikan pengaruh yang positif terhadap hasil belajar IPS, karena itu disarankan bagi tenaga pendidik/guru untuk menggunakan LCD dalam proses belajar mengajar.

\section{DAFTAR PUSTAKA}

Ahmadi, A dan Widodo S. 2003.Psikologi Belajar. Jakarta: Rineka Cipta. 
Akbar, R, Hawadi, R.S.D.W, dan Mardi W. 2001. Kreativitas. Jakarta: Gramedia Widiasarana Indonesia.

Arikunto, S. 1998. Prosedur Penelitian: Suatu Pendekatan Praktek. Jakarta: Rineka Cipta.

Arsyad. (2002). Media Pembelajaran, Jakarta: Ciputat Pers.

Kunandar. (2009). Evaluasi Pembelajaran. Yogyakarta : Multi Pressindo.

Kasihani. 2006. Psikologi Perkembangan. Bandung: Pustaka Setia.

Hadari Nawawi (1998). Administrasi sekolah. Jakarta : Galio Indonesia

Hamalik, Oemar. 2003. Motivasi dan Kreativitas dalam Pembelajaran. Surabaya: Usaha Nasional.

Nasution, Teknologi Pendidikan, Bandung: CV Jemars, 1982

Tiro. 1992. Metode Penelitian. Jakarta : Ghalia Indonesia

Syah.2007. Efektivitas Belajar dan Pembelajaran. Jakarta: Gramedia Pustaka Utama.

Susilowati.2007. Hubungan Antara Kreativitas Belajar dengan Prestasi Belajar.Skripsi. Padang: Universitas Sumatera Utara.

Suryabrata, Sumardi. 2001. Metode Penelitian. Yogyakarta : Pustaka Pelajar

Sardiman.(1996). Interaksi dan Motivasi Belajar Mengajar. Jakarta: PT. Grafindo.

Sadiman, Arif dkk, Media Pendidikan, Jakarta: PT Raja Grafindo Persada, 1986.

Sudjana, Nana, Media Pengajaran, Bandung: CV Sinar Baru, 1991.

Tohirin (2005).Psikologi Pembelajaran Pendidikan Agama Islam.Jakarta : PT. Raja Grafindo

Suharti, 2012.Implementasi Model Pembelajaran ARIAS dalam Pembelajaran Matematika pada Siswa Kelas VIII.A SMPN 6 SINJAI.Skripsi tidak diterbitkan. Makassar: Universitas Muhammadiyah Makassar. 